\title{
Dir el dret: comprensibilitat i excés nominal, un repte pendent
}

\author{
Agustí Pou Pujolràs \\ Departament de Filologia Catalana i Lingüística General, Universitat de \\ Barcelona \\ agustipou@ub.edu
}

Recepció: 11/03/2021, acceptació: 18/06/2021

Resum: El jurista té molt en compte els principis d'objectivitat i de precisió a l'hora de redactar els seus textos professionals. Per aquesta raó, utilitza diversos recursos que posen en relleu l'absència de la seva subjectivitat (impersonalització) i els seus coneixements tècnics (tecnicisme). Ara bé, moltes vegades el resultat contradiu l'objectiu pretès, i també la comprensibilitat del text se'n ressent. Aquesta conseqüència no desitjada no s'avé amb els corrents que advoquen per la claredat del llenguatge jurídic i pel dret a comprendre'l que té la ciutadania.

Un dels recursos més freqüentment utilitzats és la nominalització. La construcció textual basada en estructures nominals despersonalitza el text, li resta agilitat i el satura de conceptes pretesament tècnics fins a fer-lo difícilment comprensible. Una selecció d'exemples extrets de textos judicials il-lustra les formes més recurrents en aquest subllenguatge jurídic, els objectius que persegueixen i les distorsions que generen.

Paraules clau: llenguatge jurídic, objectivitat del text, impersonalització, comprensibilitat, nominalització.

\section{Decir el derecho: comprensibilidad y exceso nominal, un reto pendiente}

Resumen: El jurista tiene muy en cuenta los principios de objectividad y de precisión cuando redacta sus textos profesionales. Por esta razón, utiliza diversos recursos que ponen de relieve la ausencia de su subjectividad (impersonalización) y sus conocimientos técnicos (tecnicismo). Ahora bien, a menudo el resultado contradice el objetivo pretendido, y también la comprensibilidad del texto queda afectada. Esta consecuencia no deseada no se aviene con las corrientes que abogan por la claridad del lenguaje jurídico y por el derecho a comprenderlo que tiene la ciudadanía.

Uno de los recursos más frecuentemente utilizados es la nominalización. La construcción textual basada en estructuras nominales despersonaliza el texto, le resta agilidad y lo satura de conceptos pretendidamente técnicos hasta hacerlo difícilmente comprensible. Una selección de ejemplos extraídos de textos judiciales ilustra las formas más recurrentes en este sublenguaje jurídico, los objetivos que persiguen y las distorsiones que generan.

Palabras clave: lenguaje jurídico, objetividad del texto, impersonalización, comprensibilidad, nominalización 


\section{Writing the law: Comprehensibility and nominal excess, a challenge}

to resolve

Abstract: Lawyers take the principles of objectivity and precision into account when drawing up their professional texts. For this reason, they use several resources that emphasise the absence of their subjectivity (impersonalisation) and their technical knowledge (technical terms). However, many times the result contradicts the supposed objective, affecting the text's comprehensibility. This unintended consequence is not compatible with the intellectual currents that advocate for the clarity of legal language and citizens' right to understand it.

One of the most frequently-used resources in legal texts is nominalisation. Textual constructions based on nominal structures depersonalise the text, reduce its agility and saturate it with supposedly technical concepts, making it hard to understand. A selection of examples extracted from judicial texts illustrates the most-recurring forms in this legal sublanguage, the objectives they pursue and the distortions they generate.

Keywords: legal language, text objectivity, impersonalisation, comprehensibility, nominalisation.

\section{INTRODUCCIÓ}

D’entre els llenguatges d'especialitat, el jurídic (LJ) és, probablement, un dels que presenta una interacció més gran amb els actes comunicatius quotidians de la societat. No debades, el dret ordena l'esfera de relacions en l'àmbit privat i l'organització pública de la societat.

Aquesta transcendència social sovint no és acompanyada d'una formulació comprensible per als ciutadans. La modernització del llenguatge i el bandejament de la cripticitat gremial en la llengua del dret, del «complex d'illa» de què parla Cazorla (2007: 41), ha estat un esforç paral-lel a l'aprofundiment democràtic.

Els especialistes han destacat diversos trets del LJ: el nivell de formalitat, la priorització de la funció comunicativa, l'especificitat del lèxic i, en bona mesura, del tipus textual, i, per tant, la precisió dels termes i dels textos, i l'objectivitat del discurs (Duarte 1998: 49-63; Henríquez i Varela 2010: 35-39). En aquest article ens centrem en els dos darrers aspectes.

Tot i l'evolució del LJ, trobem usos recurrents que, emparats en una pretesa objectivitat, limiten gratuïtament l'eficàcia comunicativa del text. En concret, a través de l'anàlisi d'una selecció de textos judicials, analitzarem un d'aquests recursos: l'ús d'estructures nominals associada a la construcció d'un discurs parcialment pseudotècnic.

\section{FACTORS QUE INCIDEIXEN EN LA COMPOSICIÓ DEL TEXT JURÍDIC}

\subsection{L'objectivitat del text $i$ la juridicitat}

Els diversos principis que informen l'ordenament d'un estat de dret apunten, simplificant molt els conceptes, a la certesa de la regla aplicable i a la interdicció de l'arbitrarietat a l'hora d'aplicar-la (Taranilla i Yúfera, 2011: 171). Les normes han de ser aplicades al cas concret amb subjecció màxima a l'ordenament. L'activisme de l'aplicador del dret no és ben vist pel jurista. El que justifica la feina dels operadors jurídics és que les decisions, les peticions, les opinions o les actuacions jurídiques concretes es fan a l'empara d'un conjunt de tècniques que permetin delimitar bé el supòsit de fet, seleccionar el conjunt normatiu que hi és aplicable i extreure dels enunciats de les normes les respostes que corresponen. Aquesta tasca d'interpretació confereix certesa i 
predictibilitat a l'aplicació del dret.

Aquestes idees inicials serveixen per justificar una de les característiques d'aquest llenguatge: la formulació objectiva dels enunciats i dels raonaments i el rebuig de la presa de decisions per raons d'oportunitat. La neutralitat del llenguatge emprat (Barrajón i Lavale 2013: 28) és el correlat de l'ajustament al dret de la posició defensada, manifestat a través de les diferents tècniques d'hermenèutica. L'argumentació basada en l'ordenament jurídic esdevé, doncs, essencial (Andrés Ibáñez 2001: 21-22; Cazorla Prieto 2007: 31; Campo 2019: 66). Des d'aquesta perspectiva, mostrar un llenguatge objectiu és un requeriment del bon ancoratge jurídic de l'argument esgrimit i de l'opció presa.

L'objectivitat se cerca mitjançant diverses estratègies discursives (en el sentit que, recollint Halliday, estableix Morales López, 2013). A vegades, apel-lant a l'esmentada precisió del terme o de l'enunciat (Montolío 2011: 69; González Salgado 2015: 56); d'altres, ocultant l'autoria del text sota formes impersonals o sota terceres persones que indiquen la funció de l'autor; o, altres vegades, amb nominalitzacions i altres recursos desmodalitzadors (Barrajón i Lavale 2013). I molt sovint l'objectiu del jurista que usa aquests recursos és embolcallar a través del llenguatge la narració o l'argumentació amb un halo de rigor jurídic (Castellón 2006: 187-190).

Finalment, cal fer una distinció entre dos principis rellevants, suara indicats: l'objectivitat i la precisió. El primer apunta a l'absència de prejudici personal en l'argument construït per justificar l'opció presa i l'ajustament al corpus jurídic vigent. El segon té a veure amb el bon exercici tècnic del jurista. Ara bé, tot i tractar-se de perfils conceptuals diferents, les dues aproximacions fan servir alguns recursos lingüístics semblants per «fer veure» al destinatari que el text és absolutament ajustat a dret i és, per tant, tècnicament ben construït.

\subsection{La comprensibilitat del text jurídic, requeriment democràtic}

El discurs jurídic té una dimensió social i política de primer ordre. La relació entre llenguatge del dret i ciutadania sempre ha estat complexa i plena de desafeccions (De Prada 2014; González Salgado 2009: 5). Però en la mesura que la democràcia suposa investir els ciutadans d'una dimensió participativa i garantir-los uns drets davant dels actes públics, la necessitat de fer comprensible el LJ ha esdevingut un requeriment democràtic (Mattila 2009; Sánchez Hernández 2011: 37; Núñez Sánchez 2019).

Des del sorgiment del moviment Plain English en els països de l'òrbita anglosaxona a l'entorn de la protecció als consumidors (Steinberg 1991), per bé que amb antecedents anteriors notables en l'àmbit dels textos oficials (Duarte 1998: 63), les iniciatives públiques sobre aquesta qüestió i la bibliografia generada ha estat vastíssima. Montolío en fa un bon estat de la qüestió (2019: 73-76; molt interessant també Montolío i López Samaniego 2009 i Montolío i Tascón 2020). La cristal-lització del dret a comprendre es configura com una garantia de la participació conscient i informada del ciutadà en els diferents aspectes de la seva vida que es canalitzen mitjançant les diferents formes de discurs jurídic (Poblete i Fuenzalida 2017: 121-123; Núñez Sánchez 2019; Informe 2011). En concret, a l'àmbit judicial aquest dret a comprendre revesteix una rellevància especial, incardinable a l'esfera de la tutela judicial efectiva, en la mesura que el ciutadà concernit ha de saber què se li ordena i per quin motiu (Bayo 2011: 98; Braceras i Carretero 2016a, 2016b). A l'Estat espanyol la Carta dels drets del ciutadà davant la justícia recull i explicita aquest dret (proposició no de llei, aprovada pel Congrés dels Diputats el 2002).

Strandvik assenyala que «esta comprensión constituye una condición para que los ciudadanos puedan ejercer sus derechos fundamentales, para que quieran participar en la 
vida política, para que tengan confianza en las autoridades y acaten sus decisiones» (2011: 131; en termes semblants, també 2019).

A Catalunya aquest corrent renovador va incidir en el català administratiu i jurídic de manera ben primerenca a recer de la recuperació de l'autogovern. La dècada dels 80 i 90 es va bastir un model de LJ que beu dels corrents modernitzadors i que advoca per la comprensibilitat del text jurídic (Arnall 2019). Publicacions com Llengua i Administració, després Llengua i ús, la Revista de Llengua i Dret impulsen aquesta tendència (Duarte 2011: 125-129; Cassany 2005).

La transcendència de la comprensibilitat del llenguatge dels juristes cobra encara més relleu per la funció que tenen els mitjans de comunicació en la configuració d'una opinió pública informada, peça essencial d'una societat democràtica, guiada, entre d'altres, pels principis de transparència i publicitat (De la Cuadra 1998: 92-95; Cazorla Prieto 2007: 157-163). El mitjà de comunicació passa a ser un «intermediari» d'una informació jurídica que ha de ser clara i assequible per a la ciutadania (Lenguaje jurídico en los medios, 2011).

No ens deturem ara a detallar els trets específics del discurs jurídic (des d'un punt de vista descriptiu, per exemple, Hernando Cuadrado 2003; Henríquez i Varela 2010; Carretero i Fuentes 2019: 8-13) ni les recomanacions per a la millora, àmbit en què en les diferents llengües hi ha hagut propostes força convergents. A tall d'exemple, el popular Plain English for Lawyers (Wydick, 2005; primera edició el 1978) conté solucions lingüístiques ben coincidents amb els manuals de l'àmbit del català (Estopà i Garcia, 2004), castellà (Libro de estilo de la Justicia, 2017; Libro de estilo Garrigues, 2006) o europeu (How to write clearly, 2011). També en aquest sentit, però centrat en l'àmbit judicial, cal recordar les recomanacions de la Comissió de Modernització del Llenguatge Jurídic de l'Estat espanyol (Informe 2011) o, a Catalunya, la tasca de formació en LJ desplegada pels serveis lingüístics de l'àmbit judicial.

\subsection{Objectivitat i precisió versus comprensibilitat?}

La dicotomia entre la precisió jurídica i la comprensibilitat és falsa. Prieto de Pedro referia la tensió entre seguretat i claredat, i indicava que sempre hi havia opcions per resoldre-la de manera favorable a la comprensió (1991: 133-134). La precisió jurídica no està renyida amb l'expressió clara i assequible. És més, una redacció clara contribueix a assolir una major precisió jurídica i millora la qualitat tècnica del text (Strandvik 2011: 145; Kimble 1994-1995). L’esforç per a una composició clara del text jurídic força una major claredat conceptual, circumstància que redunda en una millora tècnica (Cazorla 2016: 15). Aquesta no és, però, la percepció que encara avui evidencien molts textos jurídics, i signifiquem aquí els judicials (García i Polanco 2012; Alcaraz i Hugues 2002: 17-31), que tendeixen a emfatitzar l'expertesa a través d'una determinada expressió lingüística (Cazorla Prieto 2007: 33; De la Cuadra 1997: 4).

Conflueixen aquí la pretesa objectivitat del text amb el pseudotecnicisme. En la mesura que situem marques d'objectivació, la formulació és més tècnica, i canalitza uns continguts jurídicament precisos. La realitat, però, és que els mecanismes lingüístics emprats per acreditar la juridicitat del contingut sovint fan més complex, quan no erroni, el text, i li resten justament la precisió que diuen perseguir (González Salgado 2009 i 2015: 56; Montolío 2011: 70; Duarte 1998: 52-53).

També cal notar una circumstància que ha estat posada en relleu pels estudis sobre modalització: que un text sembli objectiu no comporta que l'exposició o l'argumentació que hi ha al darrere sigui neutra. Com indica Grau, «en els textos es produeix sovint una 
"il-lusió d'objectivitat" [...] no és el mateix l'objectivitat lingüística que la neutralitat» (Grau 2003: 358; Grau 2000: 41).

\subsection{Recursos lingüístics que articulen l'objectivitat}

Els textos jurídics se serveixen de recursos lingüístics que tenen per objectiu evidenciar l'absència de la subjectivitat de qui els compon (Artigas 2007: 29). Els recursos desmodalitzadors són les eines que serveixen al jurista per donar una imatge de més objectivitat. Hi ha diverses classificacions d'aquestes eines que graduen la presència de l'emissor en el text (per exemple, Cuenca 2007: 35-40; Grau 2003 i 2007: 14-16).

L'«esforç per rebaixar la modalització» és una constant en el text jurídic. Ara bé, molt sovint l'adopció d'aquesta perspectiva no implica ni que l'estratègia i els recursos siguin encertats, ni que la subjectivitat no es filtri a través d'altres recursos. Així, mentre que es fan servir moltes tècniques impersonalitzadores (Barrajón i Lavale 2013) o en els segments deòntics es procura que textualment la implicació personal sigui mínima (he de condemnar $i$ condemno, en nom de..., d'acord amb...), sovint hi trobem una forta càrrega apreciativa, que és un mal indicador per a la neutralitat. Com assenyala Cuenca (2007: 41), es vol donar un «to d'objectivitat» que, tanmateix, sovint és aparent.

Parem ara atenció a un dels recursos que llasta més la comprensibilitat del discurs jurídic: la nominalització.

\section{3. Ús D'ESTRUCTURES NOMINALS, OBJECTIVITAT I PSEUDOTECNICISME}

Diversos autors situen el recurs a la nominalització com un dels trets que caracteritzen el llenguatge acadèmic i tècnic (Grau 2003; Salvador 2000). Certament és un recurs rendible, ordenador, perquè crea un «objecte de discurs» que permet articular i fer progressar les idees dins del text a través de seqüències de significació que s'hi encaixen i s'hi subordinen (Méndez 2001: 1019). Proporciona un perfil tècnic al discurs (Henríquez i Varela 2010: 42). D’altra banda, però també en sintonia amb això, Barrajón i Lavale el descriuen, des de la perspectiva de la impersonalització, com a mecanisme de desagentivació (2013), que resta subjectivitat al que es diu i atorga credibilitat al discurs. En aquesta línia, sovintegen els verbs d'argumentació (resultar, comportar, implicar...) i de causa o conseqüència (causar, motivar, produir...), que enllacen els blocs nominals i tenen un comportament fortament relacional.

En tot cas, hi ha consens a considerar que és un recurs que, sobreutilitzat, causa falta de fluïdesa del text $\mathrm{i}$, al capdavall, en fa minvar la comprensibilitat (per exemple, Estopà i Garcia 2003: 45-46; Libro de estilo de la Justicia: 66). Sobre aquest efecte «espessidor», Salvador remarca que «comprimeix una gran quantitat d'informació lèxica en sintagmes nominals que assoleixen, en contrapartida, un cert grau d'opacitat, tant pel que fa a l'ancoratge temporal com a l'explicitació dels participants» (2000: 77), com també s'assenyala que aquestes estructures són inconvenients des del punt de vista comunicatiu per la dificultat per descodificar-ne el contingut (Méndez 2001: 1019).

Tot seguit recollim alguns exemples de nominalització extrets de textos judicials. ${ }^{1}$

\section{A. El text tecnificat}

La nominalització que ens plantegem aquí és sobretot la del substantiu deverbal i els

\footnotetext{
${ }^{1} \mathrm{El}$ corpus emprat són sentències d'òrgans judicials catalans que s'han tramès als serveis lingüístics de l'àmbit judicial, del Departament de Justícia, tant en català com en castellà. Aquestes resolucions han estat traduïdes o corregides, però el text que faig servir aquí és l'original. Així mateix, agraeixo a Anna Estopà la selecció dels fragments que han constituït la base dels exemples d'aquest treball.
} 
complements que l'acompanyen. Una pràctica massa recurrent en aquest sentit confereix al text un aspecte pseudotècnic que, sense perdre cap contingut d'especialitat ni de formalitat, podria haver estat formulat de manera molt més comprensible.

Reproduïm aquest il-lustratiu fragment d'una sentència i n’indiquem els segments nominalitzats.

(1) Al no adoptar el Sr. XXX (a) una conducta diligente y (b) con valoración del resto de las circunstancias concurrentes en que se apoya la mala fe de la hija, mediante (c)una ponderación de ambas conductas no podemos concluir que proceda (d) $\underline{\text { la }}$ retroacción del pronunciamiento de extinción de los alimentos (e)al momento de presentación de la demanda, pues, en ambas partes, concurre (f) una conducta no totalmente aceptable, a los efectos pretendidos, que conlleva ( $\mathrm{g}$ ) la desestimación de la petición del recurrente $(h)$ de retroacción de los efectos de la presente resolución (i)a la presentación de la demanda.

Com es pot apreciar, la densitat de les diferents unitats marcades és molt alta i l'acció verbal queda relegada a un pla molt secundari. De fet, es tracta d'un text on el predomini del concepte sobre l'acció en compromet greument la llegibilitat. En general, en els textos utilitzats en aquest treball advertim freqüentment una nominalització artificiosa. Posem-ne un exemple.

(2) Totes aquestes dades queden reflectides com a fets provats en la sentència objecte de recurs i l'omissió de la no minoració del preu de la venda de l'ímmoble, com a bé subrogat, a detraure de l'actiu patrimonial del Sr. XXX, és una qüestió jurídica...

L'«omissió de la no minoració del preu de la venda de l'immoble» recull en una frase no oracional un concepte sense càrrega terminològica («la part processal va ometre que no s'havia abaixat el preu de la venda de l'immoble»), però que es presenta com a exercici de precisió que recull i sintetitza les circumstància que s'acaben d'exposar en passatges anteriors.

Són recurrents les estructures de verb buit o funcional + substantiu deverbal + complement del nom:

(3) ...es produïa l'extinció del gravamen.

També trobem en els textos l'estructura nom/verb + per a + sintagma nominalitzat.

(4) ...no té transcendència per a la resolució de la litis...

(5) ...es va assenyalar per a deliberació de l'admissió o inadmissió davant d'aquesta Secció.

El cas (5), tot i contenir termes amb contingut tècnic, presenta una redacció que, a banda de cacofònica, obstaculitza la comprensió i és innecessària davant la millora que obtenim fent servir els verbs, a més d'altres incorporacions que poden precisar el significat del segment: «...es va assenyalar dia per deliberar si l'admetíem o no».

O estructures amb preposició, com aquesta de caràcter temporal i amb una formulació parcialment impersonalitzadora:

(6) ...suspendió la tramitación del mismo hasta la resolución de la cuestión prejudicial planteada por otros órganos judiciales españoles ante el TJUE. 
Podria ser reformulada de la manera següent: «...hasta que el TJUE resolviera la cuestión que plantearon otros órganos judiciales españoles».

La fluïdesa del text també queda compromesa amb estructures nominals amb valor referencial (casos 7 i 8) o l'ús sovintejat d'un possessiu que acompanya el substantiu deverbal (casos 9 i 10).

(7) ...la dita falta de legitimació activa...

(8) ...personado uno de los comuneros, por diligencia de ordenación, se deniega dicha personación...

(9) ...deixant sense efecte el dret de retenció exercit per XXX i la nul-litat dels actes subsegüents al seu exercici.

(10) Procede la condena en costas a la recurrente [...], sin imposición de las costas derivadas del recurso de casación dada su estimación.

Aquest últim cas també mostra un dels recursos nominals habituals, la preposició amb o sense seguida del substantiu, que tractem més endavant.

En general, la nominalització en els textos exposats genera mots aparentment especialitzats, que moltes vegades, però, tenen una escassa vàlua conceptual per al dret $\mathrm{i}$ no passen de ser un conjunt lèxic parajurídic, recurrent i comunicativament entorpidor. Alcaraz i Hugues, seguint Fowler, tracten i il-lustren el fenomen de la relexicalització, que entenen com «l'encunyament de conceptes especialitzats que amb freqüència transporten valors foscos o misteriosos» (2002: 31). Vegem-ne alguns exemples.

(11) ...la extinción o decadencia del título posesorio...

(12) Frente a dicha etiología delictiva no puede admitirse la probabilidad causal de que el mecanismo de causación fuera otro y además ajeno al acusado...

(13) El present recurs contenciós administratiu té per objecte la pretensió anul-latòria exercida a nom de XXX...

\section{B. L’autoria equívoca}

Treure les marques de subjectivitat és un instrument recurrent en els textos judicials. La nominalització aconsegueix aquesta finalitat sovint, però amb un resultat estilísticament alambinat.

(14) ...en ambdues parts concorre una conducta no totalment acceptable, als efectes pretesos, que comporta la desestimació de la petició del recurrent...

(15) ...sólo en caso de que se diera una clara y hasta grosera desviación del resultado probatorio podría afirmarse una vulneración del artículo 24 de la Constitución Española.

(16) La desestimación del primer motivo del recurso de casación comporta el rechazo íntegro de la demanda, sin necesidad de entrar al examen de los motivos segundo y tercero del recurso de casación deducido.

A (14) la identitat de l'autor (el tribunal que desestima) resta opaca per la col-laboració entre un verb que estableix una conseqüència (comporta) i l'objectivació de l'acció (desestimació). A (15) continua la desimplicació. La vulneració de l'article 24 seria 
produïda per un jutge, però la identitat de l'agent torna a quedar invisible per la conversió nominal, per la tecnificació gratuïta i per la impersonalització del verb. En el cas (16), sobre la base del mateix tipus de verb, s'omet qui desestima, qui rebutja i qui examina.

En tots tres exemples se significa, doncs, que el jutge no intervé en la decisió resultant, que és fruit de subsumir la conducta de la part processal en la norma que hi és aplicable. La intenció comunicativa és que la conseqüència jurídica es desvinculi de qui pren la decisió.

L'exemple següent, amb el mateix tipus de verb, gira entorn de dos arguments: el subjecte es construeix a partir d'adjectius nominalitzats i l'objecte, del possessiu més el substantiu deverbal.

(17) Téngase presente que solo la ausencia, la insuficiencia o la falta de claridad [de la motivació de la sentència] comportarían su [del recurs] estimación.

L'objectivació encara s'aprecia més en verbs impersonals amb un mandat o en verbs buits, molt presents a la part dispositiva de les sentències.

(18) No procede la imposición de las costas del presente recurso extraordinario de infracción procesal y de casación tras la estimación parcial de ambos.

(19) Toda persona criminalmente responsable de un delito debe proceder a la reparación de los perjuicios.

(20) Solo así, cabrá estimar la existencia de un consentimiento válido...

La forma «no procede» (18) evita l'assumpció de la decisió i trasllada tota la informació a la seqüència nominal «la imposición de las costas...» Una forma molt més directa fora «No imponemos las costas...» En la mateixa frase també trobem un altre recurs interessant. La preposició temporal tras més el substantiu «estimació». De fet, el sentit del segment és causal («perquè els hem estimat parcialment»), però en establir una relació temporal l'autor aconsegueix visibilitzar encara més la desimplicació.

En l'exemple (19) (construcció de verb buit) la nominalització no oculta l'autor, perquè el subjecte de l'acció del substantiu no és qui redacta el text, però dilata innecessàriament l'oració. A (20) l'objectivació a partir del verb existir («existencia de un consetimiento válido»), que aporta un escàs contingut semàntic, reforça la impersonalització de cabrá.

Esmentem l'estructura habitual amb/sense + substantiu + de, que en realitat molt sovint amaga una oració coordinada. Aquesta estructura és freqüent en la part dispositiva dels documents.

(21) CASAMOS la sentencia recurrida y con revocación de la misma, procede la estimación de la demanda...

(22) Notifíqueses esta resolución, significándole que contra la misma cabe interponer recurso de reposición en el término del quinto día desde su notificación previa constitución de depósito para recurrir, con apercibimiento de pararle el perjuicio a que hubiere lugar en derecho.

(23) DESESTIMAR el recurs de cassació interposat [...], amb confirmació de la part dispositiva d'aquesta, és a dir, desestimant la demanda, sense especial pronunciament de les costes del recurs a la recurrent, $i$ amb pèrdua del dipòsit constituït per recórrer.

A banda de l'ús erràtic del gerundi i de l'agramaticalitat final del text, la construcció

Dir el dret: comprensibilitat i excés nominal, un repte pendent

Agustí Pou Pujolràs (2021)

Llengua, Societat i Comunicació, núm. 19 http://revistes.ub/index.php/LSC/

lsc@ub.edu http://creativecommons.org/licenses/by-nc-nd/4.0 doi:10.1344/LSC-2021.19.3 
amb preposició serveix per anar sumant seqüències nominalitzades, en detriment de l'eficàcia comunicativa. En l'últim exemple, si personalitzem el text, el resultat pot ser el següent: «...i en confirmem la part dispositiva; per tant, desestimem la demanda i no imposem les costes del recurs a la recurrent, que perd el dipòsit que va constituir per recórrer».

Altres formes habituals són locucions prepositives com la següent:

(24) ...no se suspende su ejecutividad, sin periuicio de la adopción de medidas cautelares.

En aquest sentit, proliferen formes preposicionals artificioses i poc entenedores, que contenen un significat final:

(25) L'advocada de la Generalitat de Catalunya va presentar l'escrit el 25 de gener de 2019, en preparació del recurs de cassació contra la Sentència de 16 de desembre de...

(26) S'adopta la mesura en aplicació de l'article 124...

També mereix una consideració la combinació d'un correferent per designar el mateix autor del document i el substantiu deverbal precedit del possessiu.

(27) El Ministeri Fiscal no ratifica el recurs, s'hi oposa i reclama d'aquesta alcada la seva desestimació.

Sens dubte, la solució «El MF no ratifica el recurs, s'hi oposa i reclama que el desestimem» és molt més eficient.

Finalment, reproduïm un exemple d'impersonalització que lliga diverses seqüències nominalitzades que injecten una densitat incompatible amb la funcionalitat del text jurídic.

(28) ...no té transcendència per a la resolució de la litis, atès que la dita falta de legitimació activa s'ha rebutjat motivadament en l'anterior fonament partint de l'excepcionalitat del cas sotmès a enjudiciament, de l'omissió del cens en el procediment expropiatori i que simultàniament a l'expropiació es produïa l'extinció del gravamen amb pagament de la redempció als censualistes amb part del preu just.

En conjunt, sobre les estructures nominalitzades són ben pertinents les paraules de Vicent Salvador (2000: 78) quan assenyala que «és fàcil que la síndrome que el conjunt dels trets conforma s'hipostasii de manera inconvenient i gairebé caricaturesca com a estil burocratitzat. En general, un dels efectes d'aquesta densificació és una certa ambigüitat de sentit i la pèrdua de llegibilitat entre el públic poc ensinistrat en aquestes estratègies. D'aquí ve l'obscurantisme i l'aparença de prestigi dels discursos que abusen del procediment. I d'aquí l'intent de fer més transparent el discurs administratiu i fins i tot el científic, en la mesura que el saber científic -i les seves aplicacions tecnològiques- no poden sostreure's a un control democràtic de fons».

\section{REFLEXIÓ FINAL}

Els juristes volen formular els seus textos amb objectivitat. Aquesta manera de fer escau a l'aplicació del dret, que és la conformació rigorosa dels arguments, de les posicions defensades i de les decisions a la normativa vigent. Alhora, el professional també vol actuar amb la màxima cura en els termes i expressions que utilitza. La precisió del seu llenguatge acredita la bona pràctica de l'ofici.

Dir el dret: comprensibilitat i excés nominal, un repte pendent Agustí Pou Pujolràs (2021)

Llengua, Societat i Comunicació, núm. 19 http://revistes.ub/index.php/LSC/

lsc@ub.edu http://creativecommons.org/licenses/by-nc-nd/4.0 doi:10.1344/LSC-2021.19.3 
En una societat democràtica l'aplicació del dret no solament ha de ser argumentada, sinó que, sobretot, ha de poder ser compresa. El dret a comprendre forma part de la transparència. El llenguatge del dret té un gran impacte social i està vinculat a la concepció democràtica de l'exercici del poder i de les relacions socials. Tanmateix, s'esdevé amb freqüència que, per materialitzar l'objectivitat i la precisió en el text, el professional utilitza recursos lingüístics que no assoleixen els objectius pretesos.

La nominalització és necessària per canalitzar i ordenar continguts tècnics i acadèmics, però usar-la desmesuradament condueix a la impersonalització excessiva, que obstaculitza la lectura i és contrària a la mateixa necessitat de motivació dels textos jurídics. També porta a construccions pseudotècniques que, al capdavall, perjudiquen la propietat del discurs.

\section{REFERÈnCIES BiBLIOGRÀFIQUES ${ }^{2}$}

Alcaraz Varó, Enrique; Hugues, Brian (2002). El español jurídico. Barcelona: Ariel.

ANDRÉs IbÁÑEZ, Perfecto (2001). «La argumentación probatoria y su expresión en la sentencia». A: Bayo Delgado, Joaquín (coord.). Lenguaje Forense. Madrid: Consejo General de Poder Judicial (Estudios de Derecho Judicial, 32), 9-34.

Arnall Duch, Anna (2019). Llenguatge jurídic català: estat de la qüestió i propostes de futur. Estudis sobre la variació terminològica, la història, els recursos, el model lingüístic i l'ús del LJC. Tesi. Universitat Pompeu Fabra.

$<$ https://www.tdx.cat/handle/10803/667603\#page=1>

Artigas, Rosa (2007). «Sobre modalització i context». Articles. Revista de Didàctica de la Llengua i de la Literatura, 42, 22-32.

<https://www-grao-com.sire.ub.edu/es/producto/sobre-modalitzacio-i-context-aro4215 $\underline{024>}$

BARRAJÓn López, Elisa; LAVALE ORTiz, Ruth M. (2013). «Los recursos de impersonalidad en el lenguaje jurídico y en el lenguaje médico». Revista de Español Vivo, 99, 25-50.

Braceras, Natividad; CARretero, Cristina (2016). «Por una justicia comprensible para el ciudadano». Confilegal (24 de novembre de 2016).

<https://confilegal.com/20161124-justicia-comprensible-ciudadano/>

-- (2016). «Una justícia moderna debe ser una justícia comprensible», Confilegal (5 de setembre de 2016).

<https://confilegal.com/20160905-una-justicia-moderna-una-justicia-comprensible/>

CAmpo Moreno, Juan Carlos (2019). «El futuro de la modernización del lenguaje jurídico». Revista del Ministerio Fiscal. Lenguaje jurídico y comunicación, 8, 58-71.

<https://www.fiscal.es/documents/20142/b35363aq-d8ad-c67c-0867-abo68a10762e>

CARretero GonzÁlez, Cristina (2015). «La claridad y el orden en la narración del discurso jurídico». Revista de Llengua i Dret, 64 63-85.

$<$ http://dx.doi.org/10.2436/20.8030.02.116>

Carretero GonzÁlez, Cristina; Fuentes Gómez, Julio Carlos (2019). «La claridad del lenguaje jurídico». Revista del Ministerio Fiscal. Lenguaje jurídico y comunicación, 8, 7-40.

CASSANY, Daniel (2005). «Plain Language in Spain». Clarity, 53, 41-44.

$<$ https://www.researchgate.net/publication/274311250 Plain language in Spain>

${ }^{2}$ Tots els enllaços han estat consultats el 2 de març de 2021.

Dir el dret: comprensibilitat i excés nominal, un repte pendent

Agustí Pou Pujolràs (2021)

Llengua, Societat i Comunicació, núm. 19 http://revistes.ub/index.php/LSC/

lsc@ub.edu http://creativecommons.org/licenses/by-nc-nd/4.0 doi:10.1344/LSC-2021.19.3 
Castellón Alcalá, Heraclia (2006). «Empleos actuales del lenguaje administrativo. Enfoques recientes de estudio». Revista de Llengua i Dret, 46, 181-203.

<http://revistes.eapc.gencat.cat/index.php/rld/article/view/808/n46-castellon-es.pdf >

Cazorla Prieto, Luis María (2007). El lenguaje jurídico actual. Cizur Menor: Thomson Aranzadi.

-- (2016). «El lenguaje de las sentencias». Abogados. Revista del Consejo General de la Abogacía, 98, 14-16.

<https://www.abogacia.es/wp-content/uploads/2016/06/download-98.pdf>

Comissió Europea (2011). How to write clearly (en tots el idiomes oficials de la UE).

$<$ https://op.europa.eu/en/publication-detail/-/publication/c2dab20c-0414-408d-87b5-d d3c6e5dd9a5>

Cuenca Ordinyana, Maria Josep (2007). «Modalització i text argumentatiu». Articles. Revista de Didàctica de la Llengua i de la Literatura, 42, 33-43.

$<$ https://www-grao-com.sire.ub.edu/es/producto/modalitzacio-i-text-argumentatiu-aro 4215027>

De la Cuadra Fernández, Bonifacio (1998). «Visión periodística del lenguaje judicial». A: Bayo Delgado, Joaquín (dir.) Lenguaje judicial. Madrid: Consejo General del Poder Judicial, 87-108.

Duarte Montserrat, Carles (1998). «Lenguaje adminisrativo y lenguaje jurídico». A: Bayo Delgado, Joaquín (dir.). Lenguaje judicial. Madrid: Consejo General del Poder Judicial, $39-85$.

-- (2011). «El lenguaje jurídico catalán, entre la tradición y la modernidad». A: MonToLío, Estrella (ed.). Hacia la modernización del discurso jurídico. Barcelona: Publicacions i Edicions UB, 125-130.

Duarte, Carles; MarTínez, Anna (1995). El lenguaje jurídico. Buenos Aires: AZ Editora.

Estopà Casals, Anna; Garcia Ginestà, Cristina (2003). Manual de llenguatge judicial. Barcelona: Generalitat de Catalunya. Departament de Justícia i Interior.

$<$ http://justicia.gencat.cat/web/.content/documents/arxius/doc 15900972 1.pdf $>$

García Asensio, M. Ángeles; Polanco, Fernando (2011). «Solemnidad, formalidad e (in)inteligibilidad. La selección léxica y la normativa lingüística en la redacción de documentos judiciales». A: Montolío, Estrella (ed.). Hacia la modernización del discurso jurídico. Barcelona: Publicacions i Edicions UB, 195-210.

Gómez Font, Alberto; Peña Arsuaga, María (redactors) (2006). Libro de estilo Garrigues. Cizur Menor: Aranzadi (també una versió catalana de 2010).

González SAlgado, José Antonio (2009). «El lenguaje jurídico del siglo XXI». La Ley, 7209, 1-5.

$<$ https://dialnet.unirioja.es/servlet/articulo? $\operatorname{codig} 0=5110481>$

-- (2015). «Problemas de precisión del discurso jurídico (aproximación desde el ámbito de la asesoría lingüística)». Revista de Llengua i Dret, 64, 47-62.

$<$ http://dx.doi.org/10.2436/20.8030.02.115>

Grau i TARRuell, Maria (2000). «A propòsit de la subjectivitat». Llengua i Ús. Revista Tècnica de Política Lingüística, 19, 41-49.

$<$ https://www.raco.cat/index.php/LlenguaUs/article/view/127842>

Dir el dret: comprensibilitat i excés nominal, un repte pendent

Agustí Pou Pujolràs (2021)

Llengua, Societat i Comunicació, núm. 19 http://revistes.ub/index.php/LSC/

lsc@ub.edu http://creativecommons.org/licenses/by-nc-nd/4.0 doi:10.1344/LSC-2021.19.3 
-- (2003). La modalització: manifestacions de la subjectivitat lingüística en els discursos acadèmics orals $i$ escrits. Tesi doctoral. Universitat Autònoma de Barcelona.

$<$ https://www.tdx.cat/handle/10803/4830\#page=1 >

-- (2007). «Modalització i ús de la llengua». Articles. Revista de Didàctica de la Llengua i de la Literatura, 42, 9-21.

$<$ https://www-grao-com.sire.ub.edu/es/producto/modalitzacio-i-us-de-la-llengua-aro42 $\underline{15023}>$

Henríquez Salido, Maria do Carmo; Varela Portela, Concepción (2010). «La lengua especializada en la doctrina del Tribunal Constitucional». Revista de Llengua i Dret, 54, 33-78.

<http://revistes.eapc.gencat.cat/index.php/rld/article/view/2346>

Hernando Cuadrado, Luis Alberto (2003). El lenguaje jurídico. Madrid: Editorial Verbum.

KIMBLE, Joseph (1994-1995). «Answering the critics of Plain Language». Scribes Journal of Legal Writing, 5, 51-86.

MatTiLA, Heikki E.S. (2009). «Los cambios del lenguaje administrativo y jurídico en el mundo de hoy. Un balance comparativo de los últimos veinticinco años». Revista de Llengua i Dret, 51, 17-37.

<http://revistes.eapc.gencat.cat/index.php/rld/article/view/2262>

Méndez García de Paredes, Elena (2003). «Nominalización y tipo de texto». A: Estudios ofrecidos al profesor José Jesús de Bustos Tovar. (vol. 2) Madrid: Servicio de Publicaciones de la Universidad Complutense, 1015-1032.

$<$ http://hdl.handle.net/11441/25137>

Ministerio De Justicia (2011). Informe de la Comisión de modernización del lenguaje jurídico, Madrid: Ministerio de Justicia.

<https://www.administraciondejusticia.gob.es/paj/PA PAGAJgenerico/descarga/Infor me\%20de\%2ola\%20Comisi\%C3\%B3n\%20de\%20Modernizaci\%C3\%B3n\%20del\%20Leng uaje\%20Jur\%C3\%ADdico.pdf?idFile=41ae8714-a3a7-462e-b496-6da3ffcb7421>

Montolío, Estrella (2011). «La situación del discurso jurídico español. Estado de la cuestión y algunas propuestas de mejora». A: MonToLío, Estrella (ed.). Hacia la modernización del discurso jurídico. Barcelona: Publicacions i Edicions UB, 65-91.

-- (2019). «Hacer más claro el discurso judicial. Propuestas lingüísticas de optimización». Revista del Ministerio Fiscal. Lenguaje jurídico y comunicación, 8, 72-95.

<https://www.fiscal.es/documents/20142/b35363a9-d8ad-c67c-0867-abo68a10762e>

Montolío, Estrella; López SAmAniego, Anna (2008). «La escritura en el quehacer judicial. Estado de la cuestión y presentación de la propuesta aplicada en la Escuela Judicial de España». Revista Signos, 41, 33-64.

Montolío Durán, Estrella; TAScón, Mario (2020). El derecho a entender. La comunicación clara, la mejor defensa para la ciudadanía. Madrid: Los Libros de la Catarata.

Morales LóPez, Esperanza (2013). «Anàlisi del discurs i complexitat». Llengua, Societat $i$ Comunicació, 11, 6067.

$<$ https://doi.org/10.1344/LSC-2013.11.9>

Muñoz Machado, Santiago (dir.) (2017). Libro de estilo de la Justicia. Madrid: Real Academia Española de la Lengua, Consejo General del Poder Judicial, Espasa.

Dir el dret: comprensibilitat i excés nominal, un repte pendent

Agustí Pou Pujolràs (2021)

Llengua, Societat i Comunicació, núm. 19 http://revistes.ub/index.php/LSC/

lsc@ub.edu http://creativecommons.org/licenses/by-nc-nd/4.0 doi:10.1344/LSC-2021.19.3 
Nứ̃̃zZ SÁNCHEZ, Ángel (2019). «El derecho a comprender». Revista del Ministerio Fiscal. Lenguaje jurídico y comunicación, 8, 96-113.

<https://www.fiscal.es/documents/20142/b35363a9-d8ad-c67c-0867-abo68a10762e>

Peral Parrado, María (dir.) (2011). El lenguaje jurídico en los medios. Madrid: Ministeri de Justícia.

Poblete, Claudia Andrea; Fuenzalida González, Pablo (2018). «Una mirada al uso de lenguaje claro en el ámbito judicial latinoamericano». Revista de Llengua i Dret, 69, 119-138.

$<$ http://dx.doi.org/10.2436/rld.i69.2018.3051>

Prieto de Pedro, Jesús (1991). Lenguas, lenguaje y derecho. Madrid: Civitas.

SALVADOR, Vicent (2000). «L'estil nominalitzat». Caplletra, 29, 69-82.

$<$ https://ojs.uv.es/index.php/caplletra/article/view/4970>

SÁncheZ henÁndeZ, Ana (2011). «Razones y objetivos quemotivaron la creación de la Comisión de Modernización del Lenguaje Jurídico por acuerdo del Consejo de Ministros de 30 de diciembre de 2009». A: MonTolío, Estrella (ed.). Hacia la modernización del discurso jurídico. Barcelona: Publicacions i Edicions UB, 25-37.

Steinberg, Erwin R (1991). Plain Language. Principles and practice. Detroit: Wayne State University Press.

STRANDVIK, Ingemar (2011). «La modernización del lenguaje jurídico en Suecia: ¿enseñanzas aplicables a otras tradiciones». A: Montolío, Estrella (ed.). Hacia la modernización del discurso jurídico. Barcelona: Publicacions i Edicions UB, 131-149.

-- (2019). «La comunicació jurídica i la claredat. L'exemple de Suècia». Blog de la Revista de Llengua i Dret.

$<$ https://eapc-rld.blog.gencat.cat/2019/01/31/la-comunicacio-juridica-i-la-claredat-lexe mple-de-suecia-ingemar-strandvik/>

TARANILla, Raquel; Yúfera, Irene (2011). «Historias y argumentos. Operaciones textuales para narrar y argumentar en los textos judiciales». A: MonTolío, Estrella (ed.). Hacia la modernización del discurso jurídico. Barcelona: Publicacions i Edicions UB, 161-178.

WydICK, Richard C. (2005). «Plain English for Lawyers». Durham: Carolina Academic Press. 